\title{
Male copulatory success: heritability and relationship to mate fecundity in the southern green stinkbug, Nezara viridula (Hemiptera: Pentatomidae)
}

\author{
Denson Kelly McLain* \\ Nancy Brannen Marsh
}

\author{
Department of Biology, Landrum Box 8042, \\ Georgia Southern College, Statesboro, \\ Georgia 30460, U.S.A.
}

\begin{abstract}
Single male southern green stinkbugs, Nezara viridula, sequestered in mating chambers with six females varied in the number of copulations achieved. Females copulating with relatively successful males were more fecund than females copulating with less successful males. This suggests that females mating successful males receive greater nutritional rewards per mating or that their risk of contagion is reduced. There was a significant correlation between the mating success of fathers and sons. Since egg quality (hatch rate) and egg size (diameter) did not covary with male copulatory success, this correlation indicates additive genetic variation for male mating. success in a natural population. Thus, for females there appears to be a positive relationship between offspring quality and mate effects on fecundity. Additive genetic variation for mating success may be maintained by countervailing mortality selection on males imposed by a parasitoid which is attracted by male pheromones.
\end{abstract}

\section{INTRODUCTION}

Sexual selection arises from variation in the number of mates among individuals of the same sex (Darwin, 1871). Female choice contributes to variation in the mating success of males in many organisms (Trivers, 1985), including some insects (Thornhill and Alcock, 1983). Female preferences are selected to maximize immediate fecundity (Kirkpatrick, 1985) and may entail choice for males offering nutritional rewards that defray the cost of egg production (e.g., Butlin et al., 1987; Sakaluk, 1985; Gwynne, et al., 1984). Females also may be selected to choose males on the basis of their potential genetic contributions to progeny (Hamilton and Zuk, 1982; Searcy, 1982; Borgia, 1979). Females possessing and exercising preferences for attractive mates might have more attractive sons than nonchoosy females (Heisler, 1985).

Additive genetic variation for attractive male traits exists in some insect populations (Hedrick, 1988 and references therein). This genetic variation or correlated genetic variation may be expressed in the competitiveness (Partridge, 1980; Taylor et al., 1987) and, ultimately, reproductive success of offspring. However, the dual effects of male attrac-

\footnotetext{
* To whom correspondence should be addressed.
}

tiveness on female fecundity and offspring reproductive success are unknown for any species. The present study examines both the heritability of male mating success and the correlation between male success and female fecundity in the southern green stinkbug, Nezara viridula (L.). Thus, the present study addresses whether or not female choice for genes promoting offspring competitiveness is necessarily at odds with choice for male investment (e.g., Burley, 1988; Weatherhead and Robertson, 1979).

\section{METHODS}

\section{Male copulatory success}

Southern green stinkbugs, $N$. viridula, were reared in the laboratory from the eggs of 30 females collected in mid-April (1988) from wild mustard growing in an abandoned pasture in Clito, Georgia (U.S.A.). Forty sets of six virgin females and one virgin male, 10 days old as adults at the initiation of the experiment, were housed in 1-litre mason jars. Copulating pairs were sequested into $\frac{1}{2}$-litre cartons where the mated female remained for the duration of her life. The mated male was returned to the unmated females remaining in the jar from which he came. Both jars and cartons were 
supplied with two pole beans which served as both a food and water source. Fresh beans were substituted for old beans every 5 days. Insects were maintained on a $14 \mathrm{~L}: 10 \mathrm{D}$ photophase at $20^{\circ} \mathrm{C}$ and 80 per cent $\mathrm{RH}$. Males and females were placed in jars at random with regard to size. All seven adults housed together had different mothers. This arrangement reduced the potential for inbreeding depression among progeny used in the heritability estimates described below. Since experimental females did not share the same mother, they had been reared in different jars. Thus, any inadvertent environmental influence during development on the willingness of females to mate should have had minimal effect on the number of females a male mated. Since the placement of jars on racks in the environmental chamber was randomized daily and since all jars were supplied identically, variation in the number of females mated was not due to environmental variation.

Male-male competition could not be expressed in the present experiment. Therefore, differences among males in the number of females mated may be ascribed to variation in the attractiveness and staying power or general vigour of males. Copulatory success of a male is measured as the number of females mated within 30 days after the initiation of the experiment. Males copulating with all six females within 30 days were supplied with a seventh female. However, none of the males mated a seventh time. In addition to the number of females copulated, the size of each male was also determined. Here, male size refers to the width across the pronotum at the level of the lateral angles. Width was measured with an ocular micrometer to the nearest $0 \cdot 125 \mathrm{~mm}$. Measurements were made after the experiment had concluded.

\section{Heritability of male success}

The heritability of male copulatory success was assessed by the father/son regression on the number of females mated (Falconer, 1981). Sons were provided with the same environment as their fathers and afforded the same opportunity to mate six females. As with fathers, none of the sons mated a seventh female within the 30 days allotted for courtship and mating although several sons did mate with all six of the initially provided females. For each father, one son was randomly selected from 15 progeny (reared as described above) derived from the first egg mass of the first female mated. Forty father/son pairs were tested.
Male copulatory success could be inherited nongenetically as a consequence of nutrient transfer from male to female during copulation which impacts egg size or quality. Larger eggs might give rise to larger more competitive progeny (e.g., Johnson, 1982). Therefore, the percentage of eggs hatching and egg diameter were determined as, respectively, indices of egg quality and size. Egg diameter was measured with an ocular micrometer (1 unit $=0.01 \mathrm{~mm}$ ) at the widest point across the operculum, after hatching. Five eggs from the first egg mass laid by the first female mated were measured, two from the middle of one of the outer egg rows, two from the middle of the innermost egg row, and one positioned between the other two sets.

Variation in male reproductive success can derive from the fecundity of females mated as well as the number mated (Wade and Arnold, 1980). Relatively attractive or vigorous males may be more successful at obtaining copulations with more fecund females. Alternatively, relatively unattractive males may be selected to devote more time and energy to the courtship of more fecund females. Given these possibilities and given that females do vary tremendously in egg productivity (unpublished observations), the heritability of male reproductive success was also assessed. Reproductive success is defined as the total number of eggs laid by all the females a male mated. Heritability was estimated from the regression of son reproductive success on father reproductive success. Variation in reproductive success potentially reflects contributions from variation in male attractiveness and vigour, female fecundity and longevity, and offspring fitness (reflecting parental investment and genetic constitution). Reproductive success was determined for 22 father/son pairs.

\section{Female fecundity}

Fecundity, number of eggs laid per lifetime, was recorded for each female that a male mated. After copulation, females remained in the carton into which they had been sequestered during copulation. They were provided a fresh pole bean every five days. A $2 \mathrm{~cm}$-wide strip of white paper towel (Scott brand) was suspended from the carton lid as a surface for oviposition. The number of yolkbearing egg casings was recorded for each egg mass laid. Fecundity was determined for all females of 26 paternal and 28 filial generation males, including 22 father/son pairs. 
Throughout, statement of statistical significance implies $P<0 \cdot 05$.

\section{RESULTS}

\section{Fecundity and male copulatory success}

The fecundity of females covaried with the success of their mates. In both the paternal $(r=0 \cdot 38 ; t=$ $2 \cdot 01 ; n=26)$ and filial $(r=0 \cdot 52 ; t=2 \cdot 56 ; n=28)$ generations, the lifetime fecundity of the first female mated by a male was significantly positively correlated with the total number of females mated by the male (fig. 1; The analysis is restricted to the first female mated to maintain an independence between data points that would be compromised if the analysis incorporated multiple mates of single males). Similarly, there is a significant positive correlation between the fecundity of the last female mated and the number of copulations achieved by the male $(r=0.51 ; t=2.90 ; n=27$; data for paternal generation only). If the average fecundity of mates is regressed on male copulatory success, the correlation is positive for both paternal $(r=0 \cdot 29 ; t=1 \cdot 33 ; P>0.05 ; n=22)$ and filial generations $(r=0.74 ; t=4.67 ; P<0.05 ; n=20)$.

In the paternal generation, the average fecundity of mates of successful males (4-6 females mated) and unsuccessful males (1-3 females mated) was, respectively, $826 \cdot 1(\mathrm{SD}=366 \cdot 2 ; n=$ $39)$ and $545 \cdot 4(\mathrm{SD}=385 \cdot 3 ; n=34)$. In the filial generation, the average fecundity also differed between the mates of successful $(728 \cdot 2 ; \mathrm{SD}=$ $387 \cdot 3 ; n=57)$ and unsuccessful $(441 \cdot 4 ; \mathrm{SD}=$

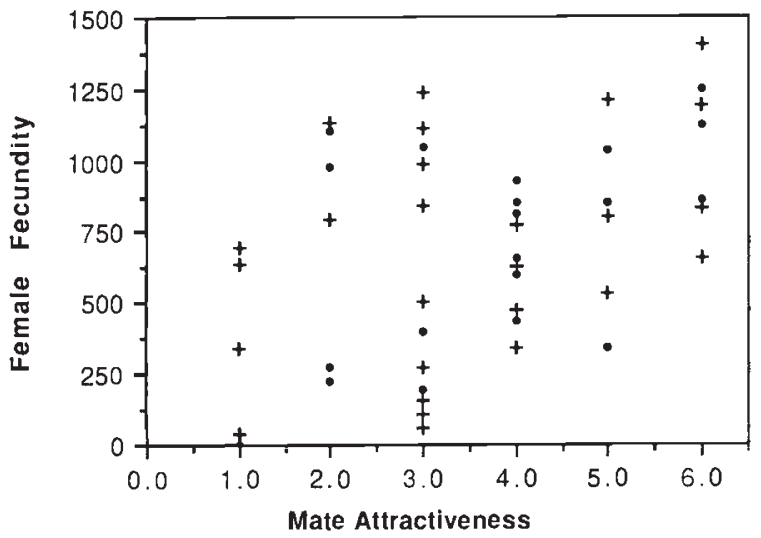

Figure 1 Relationship between female fecundity and the number of females mated by her mate (mate attractiveness) in the paternal (cross) and filial (dot) generations. The correlation between female fecundity and male copulatory success is significantly positive for both data sets.
$316 \cdot 6 ; n=28)$ males. Mean fecundity decreased between paternal and filial generations.

\section{Heritability of copulatory success}

Significant additive genetic variation for male copulatory success is present $(r=0 \cdot 36 ; t=2 \cdot 38 ; n=$ 40 ; fig. 2). Heritability, estimated as twice the slope of the regression line between paternal and filial copulatory success, was $0 \cdot 65$.

There was a significant positive correlation between the size of males and their success for fathers $(r=0 \cdot 52 ; t=3 \cdot 33 ; n=32 ;$ fig. 3$)$ but not

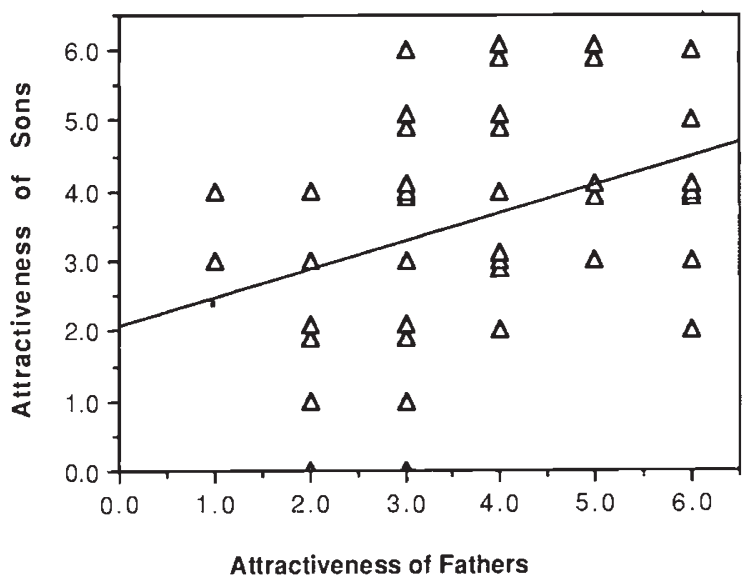

Figure 2 Relationship between the number of females mated (attractiveness) for fathers and their sons. There was a significant linear regression (regression line shown) between the copulatory success of fathers and sons.

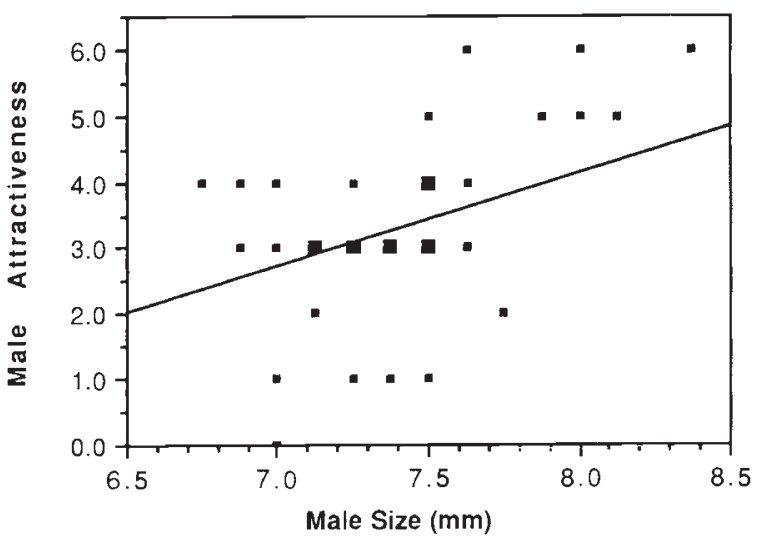

Figure 3 Relationship between male copulatory success (attractiveness) and male size (width across humeral angles) for the paternal generation. There was a significant linear regression (regression line shown) between copulatory success and size. Small square $=$ single observation, large square $=$ double observation. 
for their sons $(r=-0.11 ; t=0.61 ; n=38$; fig. 4). The regression of father's size on son's size was insignificant $(r=0.055 ; t=0.33 ; n=37$; fig. 5), suggesting that variation in size was not even partly genetically based. In 30 of 37 instances, the father was larger than the son, suggesting that environmental conditions differed between generations. The range in size for sons $(6.63-7.75 \mathrm{~mm})$ was only 69 per cent that for fathers $(6 \cdot 75-8 \cdot 38 \mathrm{~mm})$. Differences in size between generations may account for the lower mean fecundity of filial generation females relative to paternal generation females.

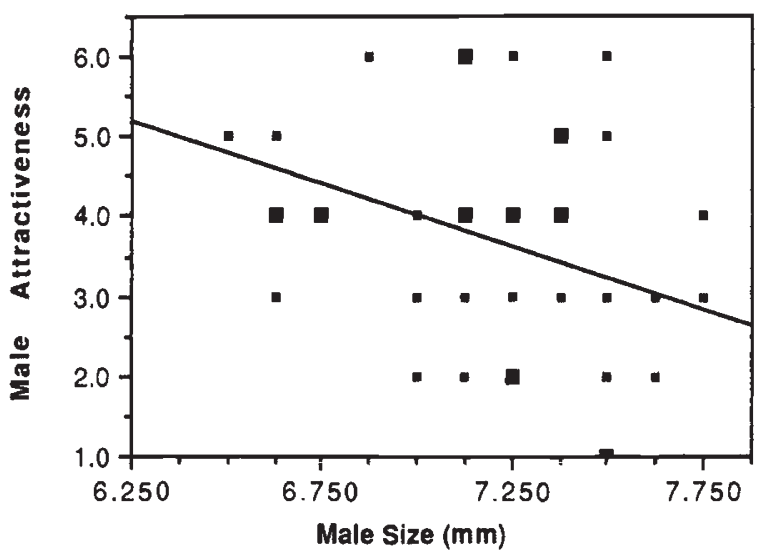

Figure 4 Relationship between male copulatory success (attractiveness) and male size (width across humeral angles) for the filial generation. The linear regression between copulatory success and size was insignificant (regression line shown). Small square = single observation, large square $=$ double observation.

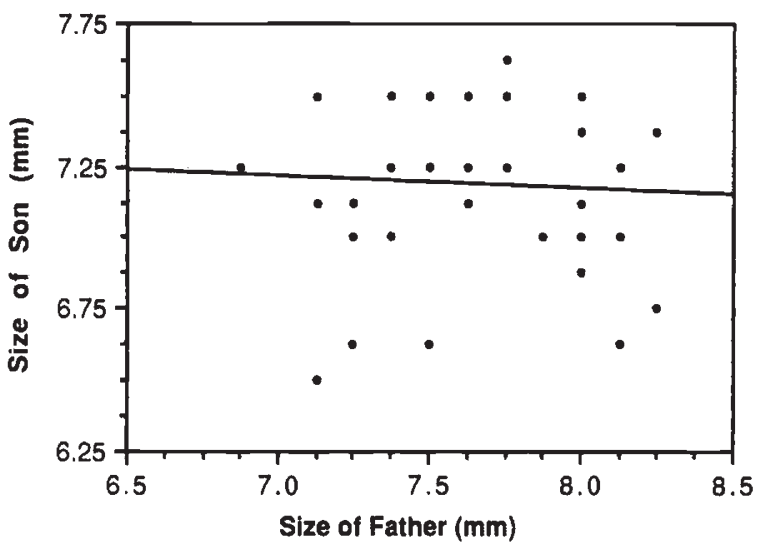

Figure 5 Relationship between the size (width across humeral angles) of fathers and their sons. The linear regression for size between paternal and filial generations was insignificant (regression line shown).
Table 1 Relationship between percentage of eggs hatching and the number of copulations obtained (A.) and ANOVA testing the significance of the relationship (B.)

\begin{tabular}{lcccccc}
\hline A. & \multicolumn{6}{l}{ Number of copulations } \\
\cline { 2 - 7 } & 1 & 2 & 3 & 4 & 5 & 6 \\
\hline Mean & 86.35 & 88.18 & 78.45 & 72.44 & 86.20 & 86.72 \\
SD & 18.74 & 6.71 & 16.31 & 17.13 & 1.84 & 4.45 \\
No. males & 2 & 5 & 11 & 8 & 2 & 5 \\
\hline
\end{tabular}

B.

\begin{tabular}{lrlll} 
Source of variation & df & MS & $F$ & $P$ \\
\hline Between groups & 5 & 237.47 & 1.20 & $>0.05$ \\
Error & 27 & 197.31 & - & - \\
\hline
\end{tabular}

Table 2 Relationship between egg diameter ( 1 unit = $0.01 \mathrm{~mm}$ ) for the first egg mass of first female mated and the number of copulations obtained (A.) and 2-level nested ANOVA of the significance of the relationship. SD $=$ standard deviation in the average egg diameter between males within a group

\begin{tabular}{lccccc} 
A. & \multicolumn{5}{l}{ Number of copulations } \\
\cline { 2 - 6 } & $1-2$ & 3 & 4 & 5 & 6 \\
\hline Mean & 76.04 & 75.56 & 75.80 & 75.60 & 75.68 \\
SD & 2.09 & 3.11 & 1.22 & 1.11 & 1.71 \\
No. males & 5 & 5 & 5 & 5 & 5 \\
\hline
\end{tabular}

B.

\begin{tabular}{lrrll} 
Source of variation & df & \multicolumn{1}{c}{ MS } & $F$ & $P$ \\
\hline $\begin{array}{l}\text { No. copulations } \\
\text { Between males }\end{array}$ & 4 & 0.93 & 0.34 & $>0.05$ \\
(within groups) & 20 & 19.77 & 7.24 & $<0.05$ \\
$\begin{array}{l}\text { Error } \\
\text { (within egg mass) }\end{array}$ & 100 & 2.73 & - & - \\
\hline
\end{tabular}

The percentage of eggs hatching was not significantly different $(P>0.05)$ between groups of males experiencing different levels of copulatory success (table 1 ). The average percentage hatching was $85 \cdot 39(\mathrm{SD}=7 \cdot 54 ; n=28)$.

Egg diameter did not vary significantly $(P>$ 0.05 ) among males experiencing different levels of copulatory success (table 2). However, within groups of males experiencing the same copulatory success, there was significant heterogeneity in egg size (table 2).

\section{Reproductive success}

Male reproductive success, the total number of eggs laid by all females mated by a male, was positively correlated between father and son $(r=$ $0.432 ; t=2 \cdot 14 ; n=22$; fig. 6 ). For both fathers 


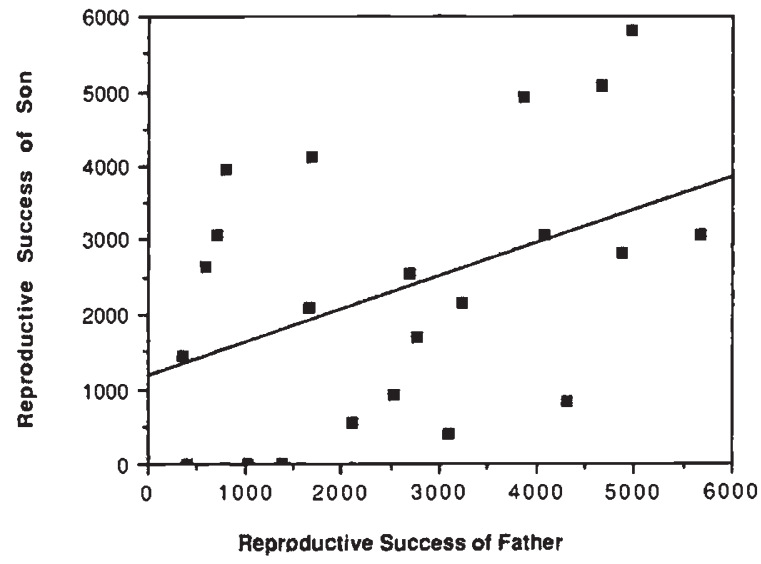

Figure 6 Relationship between the reproductive success (total number of eggs laid by all females mated) of fathers and sons. There was a significant positive linear relationship (regression line shown) between the reproductive success of fathers and sons.

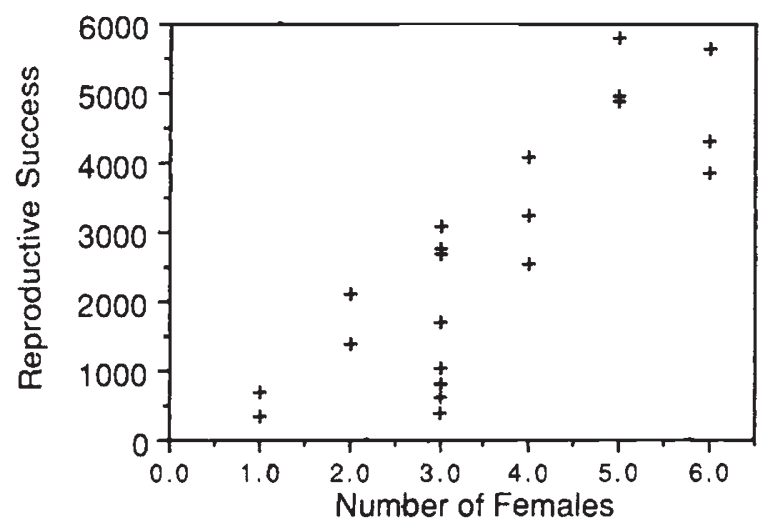

Figure 7 Reproductive success (total number of eggs laid by all females mated) of paternal generation males as a function of the number of females mated.

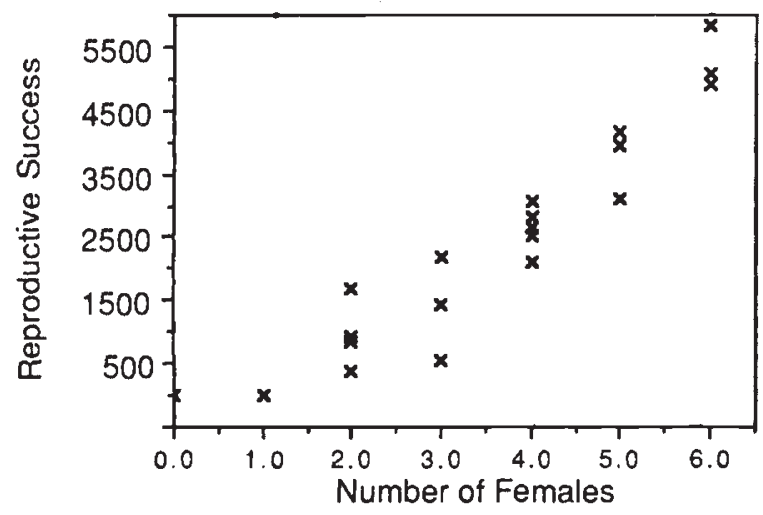

Figure 8 Reproductive success (total number of eggs laid by all females mated) of filial generation males as a function of the number of females mated. (fig. 7) and sons (fig. 8), there was a significant positive relationship between the number of females mated and reproductive success. While females of more successful males were more fecund, the correlation between number of mates and reproductive success varied little when reproductive success was regressed on number of mates as untransformed (fathers: $r=0.84, t=7.01, P<$ 0.05 ; sons: $r=0.94, t=12.30, P<0.05)$ or squareroot transformed data (fathers: $r=0.82, t=6.33$, $P<0.05$; sons: $r=0.96, t=14.65, P<0.05)$.

\section{DISCUSSION}

The results reveal that a double advantage accrues to females that mate successful males. First, their immediate fecundity, the number of eggs produced, is enhanced. This is indicated by the positive correlations between copulatory success and mate fecundity. Second, their sons experience enhanced copulatory success, potentially increasing the number of grandoffspring per male offspring. Only a few studies have documented correlations between male mating success and offspring competitiveness (Taylor et al., 1987; Partridge, 1980; but see Boake, 1985; Shaeffer et al., 1984). The present study suggests that male copulatory success is genetically inherited. Nongenetic paternal inheritance of copulatory success appears not to account for the correlation between paternal and filial copulatory success since neither egg quality (indexed by hatch rate) nor egg size (indexed by diameter) covaried with copulatory success. Male reproductive success was positively correlated with copulatory success and, thus, also exhibited apparent heritable variation.

These results are consistent with observations that variation in male traits associated with mating success often has high heritability (Hedrick, 1988; Butlin and Hewitt, 1986; Carson, 1985; Carson and Lande, 1984; Endler, 1983; reviewed in Cade, 1984). While episodes of strong directional selection on sexually selected traits could deplete genetic variation (Maynard Smith, 1985, 1978; Partridge and Halliday, 1984), additive genetic variation may be maintained by polygenic mutation (Lande, 1980a; Turelli, 1984), fluctuating selection pressures (Felsenstein, 1976), and countervailing selection on genetically correlated characters (Lande, 1980b; Arnold and Wade, 1984). It is, however, possible that heritable variation expressed in the laboratory may not be expressed in the wild (McLain, 1987; Cade, 1984). 
Additive genetic variation for mating and reproductive success may reflect an equilibrium between sexual and viability selection (Lande, 1981; Kirkpatrick, 1982; Lande and Arnold, 1985; Seger, 1985). At equilibrium, heritabilities for sexually selected traits may be high (Wilkinson, 1987). The parasitoid, Trichopoda pennipes (Diptera: Tachinidae), is attracted to southern green stinkbugs via a pheromone produced by males and to which both males and females respond (Harris and Todd, 1980; Todd, 1989). Parasitization reduces viability and fecundity of bugs (Shahjahan, 1968). Since male pheromones are a component of sexual attractiveness, more attractive males may suffer increased levels of infestation resulting in countervailing viability selection. For example, large males, which may be more attractive to females than small males, suffer greater levels of parasitization than small males (McLain, 1980 and 1987).

Enhanced fecundity of females mating successful males may compensate for their own increased risk of parasitization during courtship and copulation with males that are themselves more attractive to parasitoids. The correlation between male mating success and female fecundity may be caused by courtship feeding (e.g., Gwynne, 1984 and 1986). Stinkbugs produce both fertilizing and giant, nonfertilizing sperm (Schrader, 1960), the latter of which may function as a nutritional source to females (Sivinsky, 1984; Kasule, 1988).

Male attractiveness and the quantity, if any, of nutritional rewards to females might be correlated through male health, affected, perhaps, by levels of parasitization (e.g., Zuk, 1987 and 1988; Jaenike, 1988). Less parasitized males may have more energy to allocate to pheromones and to courtship feeding. Females also may be selected to prefer less parasitized males to reduce their risk of contagion. Since females mated only once but produced batches of eggs approximately weekly for as long as $270 \mathrm{~d}$, it is unlikely that male nutritional contributions could have had direct impact on a substantial proportion of female reproductive effort. However, large initial male contributions may have had long-term indirect benefits by reducing physiological stress on females when they were producing their first few clutches (Burley, 1988).

Female preferences may be based on multiple criteria including genetic and nongenetic traits (e.g., Burley, 1981). In the southern green stinkbug, courtship vigour, pheromone constituency and quantity, and song characteristics (Harris et al., 1982) could all serve as a basis for female choice (reviewed in Todd, 1989). These traits could be influenced by male size which depends on access to food during development (McLain, 1987) and may depend on the diversity and degree of infection during immature stages. Also, size might significantly impact the quantity of courtship feeding, selecting for female preference for large males even if differences in size are not genetically determined.

The results suggest that females receive both genetic (more sexually-competitive offspring) and nongenetic (enhanced fecundity) benefits from mating suçcessful versus unsuccessful males. This could result because the genetic differences influencing copulatory success affect the provisioning of resources to females. Females may prefer copulating with males offering greater quantities of resources (Thornhill, 1980; Sakaluk and Smith, 1988). Since selection on females to obtain genetic and nongenetic benefits from the same or different males will vary with the correlation at mating between genetic and nongenetic benefits (Borgia, 1979; Trivers, 1985), the present results are important in demonstrating that the correlation can be positive.

Acknowledgements This project was supported by a Georgia Southern Foundation Fellowship to D. K. McLain.

\section{REFERENCES}

ARNOLD, S. J. AND WADE, M. J. 1984. On the measurement of natural and sexual selection: theory. Evolution, 38, 709-719.

BOAKE, C. R. B. 1985. Genetic consequences of mate choice: a quantitative genetic method for testing sexual selection theory. Science, 227, 1061-1063.

BORGIA, G. 1979. Sexual selection and the evolution of mating systems. In Blum, M. S. and Blum, N. A. (eds) Sexual Selection and Reproductive Competition in Insects, Academic Press, New York, pp. 19-80.

BURLEY, N. 1981. Mate choice by multiple criteria in a monogamous species. Am. Nat., 117, 515-528.

BURLEY, N. 1988. The differential allocation hypothesis: an experimental test. Am. Nat., 132, 611-628.

BUTLIN, R. K. AND HEWITT, G. M. 1986. Heritability estimates for characters under sexual selection in the grasshopper Chorthippus brunneus. Anim. Behav., 34, 1256-1261.

BUTLIN, R. K., WOODHATCH, C. W. AND HEWITT, G. M. 1987. Male spermatophore investment increases female fecundity in a grasshopper. Evolution, 41, 221-225.

CADE, W. H. 1984. Genetic variation underlying sexual behavior and reproduction. Am. Zool., 24, 355-366.

CARSON, H. L. 1985. Genetic variation in a courtship-related male character in Drosophila sylvestris from a single Hawaiian locality. Evolution, 39, 678-686.

CARSON, H. L. AND LANDE, R. 1984. Inheritance of a secondary sexual character in Drosophila sylvestris. Proc. Natl Acad. Sci. USA, 81, 6904-6907.

ENDLER, J. A. 1983. Natural and sexual selection on color patterns in poeciliid fishes. Environ. Biol. Fishes, 9, 173-190. 
FALCONER, D. S. 1981. Introduction to Quantitative Genetics, 2nd edn. Longman, New York.

FELSENSTEIN, J. 1976. The theoretical population genetics of variable selection and migration. Ann. Rev. Genet., 10, 253-280.

GWYNNE, D. T. 1984. Courtship feeding increases female reproduction success in bushcrickets. Nature, 307, 361-363.

GWYNNE, D. T. 1986. Courtship feeding in katydids (Orthoptera: Tettigoniidae): Investment in offspring or in obtaining fertilizations? Am. Nat., 128, 342-352.

GWYNNE, D. T., BOWEN, B. J. AND CODD, C. G. 1984. The function of the katydid spermatophore and its role in fecundity and insemination (Orthoptera: Tettigoniidae). Aust. J. Zool., 32, 15-22.

HAMILTON, W. D. AND ZUK, M. 1982. Heritable true fitness and bright birds: A role for parasites? Science, 218, 384-387.

HARRIS, V. E. AND TODD, J. W. 1980. Male mediated aggregation of male, female and fifth instar southern green stinkbugs and concomitant attraction of a tachinid parasite, Trichopoda pennipes. Entomol. Exp. Appl., 27, 117-126.

HARRIS, V. E., TODD, J. W., WEBB, J. C. AND BENNER, J. C. 1982. Acoustical and behavioral analysis of the songs of the southern green stinkbug, Nezara viridula. Ann. Entomol. Soc. Am., 75, 234-249.

HEDRICK, A. V. 1988. Female choice and the heritability of attractive male traits: an impirical study. Am. Nat., 132, 267-276.

HEISLER, I. L. 1984. A quantitative genetic model for the origin of mating preferences. Evolution, 38, 1283-1295.

JAENIKE, J. 1988. Parasitism and male mating success in Drosophila testacea. Am. Nat., 131, 774-780.

JOHNSON, L. K. 1982. Sexual selection in a brentid weevil. Evolution, 36, 251-262.

KASULE, F. K. 1986. Repetitive mating and female fitness in Dysdercus cardinalis (Hemiptera: Pyrrhocoridae). Zool. J. Linn. Soc., 88, 191-199.

KIRKPATRICK, M. 1982. Sexual selection and the evolution of female choice. Evolution, 36, 1-12.

KIRKPATRICK, M. 1985. Evolution of female choice and male parental investment in polygynous species: The demise of the "sexy son". Am. Nat., 125, 788-810.

LANDE, R. 1980a. Sexual dimorphism, sexual selection, and adaptation in polygenic characters. Evolution, 34, 292-307.

LANDE, R. 1980 b. Genetic variation and phenotypic evolution during allopatric speciation. Am. Nat., 116, 463-479.

LANDE, R. 1981. Models of speciation by sexual selection on polygenic traits. Proc. Natl Acad. Sci. USA, 78, 3721-3725.

LANDE, R. AND ARNOLD, S. J. 1985. Evolution of mating preference and sexual dimorphism. J. Theoret. Biol., 117, 651-664.

MAYNARD SMITH, J. 1978. The Evolution of Sex. Cambridge University Press, Cambridge.

MAYNARD SMITH, J. 1985. Sexual selection, handicaps and true fitness. $J$. Theoret. Biol., 115, 1-8.

McLAIN, D. K. 1980. Female choice and the adaptive significance of prolonged copulation in Nezara viridula (Hemiptera: Pentatomidae). Psyche, 87, 325-326.

McLAIN, D. K. 1987. Heritability of size, a sexually selected character, and the response to sexual selection in a natural population of the southern green stinkbug, Nezara viridula (Hemiptera: Pentatomidae). Heredity, 59, 391-395.
PARTRIDGE, L. 1980. Mate choice increases a component of offspring fitness in fruit flies. Nature, 283, 290-291.

PARTRIDGE, L. AND HALlIDAY, T. 1984. Mating patterns and mate choice. In Krebs, J. R. and Davies, N. B. (eds) Behavioural Ecology: An Evolutionary Approach, 2nd edn, Sinauer, Sunderland, Mass., pp. 222-250.

SAKALUK, S. K. 1985. Spermatophore size and its role in the reproductive behavior of the cricket Gryllodes supplicans (Orthoptera: Gryllidae). Can. J. Zool, 63, 1652-1656.

SAKALUK, S. K. AND SMITH, R. L. 1988. Inheritance of male parental investment in an insect. Am. Nat., 132, 594-601.

SCHRADER, F. 1960. Evolutionary aspects of aberrant meiosis in some Pentatomidae (Heteroptera). Evolution, 14, 498508.

SHAEFER, S. W., BROWN, C. J. AND ANDERSON, W. W. 1984 Does mate choice affect fitness? Genetics, 107, s94.

SEARCY, W. A. 1982. The evolutionary effects of mate selection. Annu. Rev. Ecol. Syst., 13, 57-85.

SEGER, J. 1985. Unifying genetic models for the evolution of female choice. Evolution, 39, 1185-1193.

SHAHJAHAN, M. 1968. Superparasitization of the southern green stinkbug by the tachinid parasite Trichopoda pennipes and its effect on host survival. J. Econ. Entomol., 61, 10881091.

SIVINSKI, J. 1984. Sperm in competition. In Smith, R. L. (ed.) Sperm Competition and the Evolution of Animal Mating Systems, Academic Press, London, pp. 86-115.

TAYLOR, C. E., PEREDA, A. D. AND FERRARI, J. A. 1987. On the correlation between mating success and offspring quality in Drosophila melanogaster. Am. Nat., 129, 721-729.

THORNHILL, R. 1980. Mate choice in Hylobittacus apicalis (Insecta: Mecoptera) and its relation to some models of female choice. Evolution, 34, 519-538.

THORNHILL, R., AND ALCOCK, J. 1983. The Evolution of Insect Mating Systems. Harvard University Press, Cambridge, Mass.

TODD, J. W. 1989. Ecology and behavior of Nezara viridula. Annu. Rev. Entomol., 34, 273-292.

TRIVERS, R. L. 1985. Social Evolution. Benjamin Cummings, Menlo Park, CA.

TURELLI, M. 1984. Heritable genetic variation via mutation selection balance: Lerch's zeta meets the abdominal bristle. Theor. Pop. Biol., 25, 138-193.

WADE, M. J. AND ARNOLD, S. J. 1980. The intensity of sexual selection in relation to male sexual behaviour, female choice, and sperm precedence. Anim. Behav., 28, 446-461.

WEATHERHEAD, P. J. AND ROBERTSON, R. J. 1979. Offspring quality and the polygyny threshold: "the sexy son hypothesis". Am. Nat., 113, 201-208.

WILKINSON, G. S. 1987. Equilibrium analysis of sexual selection in Drosophila melanogaster. Evolution, 41, 11-21.

ZUK, M. 1987. The effects of gregarine parasites, body size, and time of day on spermatophore production and sexual selection in field crickets. Behav. Ecol. Sociobiol., 21, 65-72.

ZUK, M. 1988. Parasite load, body size, and age of wild-caught male field crickets (Orthoptera: Gryllidae): effects on sexual selection. Evolution, 42, 969-976. 